\title{
Opioid-Free Analgesia for Supratentorial Craniotomies: A Systematic Review
}

\author{
Denise Darmawikarta, Michel Sourour, Rachel Couban, Sriganesh Kamath, \\ Kesava KV Reddy, Harsha Shanthanna (1)
}

\begin{abstract}
Background: Post-craniotomy pain can be severe and is often undermanaged. Opioids can interfere with neurological monitoring and are associated with adverse effects. This systematic review aimed to identify measures of opioid-free analgesia and compare their effectiveness with opioid analgesia for post-craniotomy pain in patients with supratentorial tumors. Methods: EMBASE, MEDLINE, and Cochrane databases were searched from their inception to February 14, 2017, for randomized controlled trials (RCTs) evaluating opioid versus non-opioid analgesia post-supratentorial craniotomy. Two reviewers independently carried out study selection and data extraction. Risk of bias assessment was performed using the Cochrane Collaboration's tool. Outcomes were pain control (changes to pain scores or use of rescue analgesia) and adverse effects. Considering the number of studies and heterogeneity, a narrative synthesis was done without pooling and results were summarized using tables. Non-opioids were assessed for the potential to be equivalent to opioid-based analgesics for pain relief and adverse effects. Results: Of 467 RCTs, 4 met our inclusion criteria $(n=186$ patients). Patients with scalp blocks (2 RCTs) had less post-operative nausea and vomiting (PONV), but scalp block was not superior to morphine for analgesia. Acetaminophen (1 RCT) was less likely to induce PONV but provided inadequate pain relief compared to morphine and sufentanil. Dexmedetomidine (1 RCT) was not superior to remifentanil for analgesia although it delayed time to rescue analgesia. Conclusions: Limited evidence suggests that scalp blocks and dexmedetomidine have the potential to eliminate the need for opioid analgesia. Multimodal analgesia should be considered as significant opioid-sparing effects have been shown.
\end{abstract}

RÉSUMÉ : Analgésie sans opioïdes dans les craniotomies supratentorielles: revue systématique. Contexte: La douleur post-craniotomie peut être sévère et n'est souvent pas maintenue. Les opiö̈des peuvent interférer avec la surveillance neurologique et sont associés à des effets indésirables. Cette revue systématique visait à identifier les mesures d'analgésie sans opioïdes et à comparer leur efficacité à celle des analgésiques opioïdes pour le traitement de la douleur post-craniotomie chez les patients atteints de tumeurs supratentorielles. Méthodes: Les bases de données EMBASE, MEDLINE et Cochrane ont été explorées depuis leur création jusqu'au 14 février 2017 dans le cadre d'essais contrôlés randomisés (ECR) évaluant l'analgésie opioïde ou non opioïde après la craniotomie supratentorielle. Deux examinateurs ont indépendamment sélectionné les études et extrait les données. L'évaluation du risque de biais a été réalisée à l'aide de l'outil Cochrane Collaboration. Les résultats ont été un contrôle de la douleur (modification des scores de douleur ou l'utilisation d'une analgésie de secours) et des effets indésirables. Compte tenu du nombre d'études et de l'hétérogénéité, une synthèse narrative a été réalisée sans regroupement et les résultats ont été résumés à l'aide de tableaux. Les non-opioïdes ont été évalués pour leur potentiel équivalent aux analgésiques à base d'opioïdes pour le soulagement de la douleur et les effets indésirables. Résultats: Sur 467 ECR, 4 répondaient à nos critères d'inclusion ( $\mathrm{n}=186$ patients). Les patients avec des blocs de cuir chevelu 14 (2 ECR) avaient moins de nausées et de vomissements postopératoires (NVPO), mais le bloc de cuir chevelu n'était pas supérieur à la morphine pour l'analgésie. L'acétaminophène (1 ECR) était moins susceptible d'induire des NVPO, mais ne soulageait pas suffisamment la douleur par rapport à la morphine et au sufentanil. La dexmédétomidine (1 ECR) n'était pas supérieure au rémifentanil pour l'analgésie, bien qu'elle ait retardé le délai de récupération de l'analgésie. Conclusions: Des preuves limitées suggèrent que les blocs du cuir chevelu et la dexmédétomidine pourraient éliminer le besoin d'une analgésie opiö̈de. Une analgésie multimodale doit être considérée, car des effets importants, qui permettent d'épargner les opioïdes, ont été démontrés.

Keywords: Non-opioid analgesia, Craniotomy, Multimodal analgesia, Neurosurgery

doi:10.1017/cjn.2019.57

Can J Neurol Sci. 2019; 46: 415-422

\section{INTRODUCTION AND BACKGROUND}

The management of post-craniotomy pain is an important yet generally overlooked area of research. This is in part due to the assumption that post-craniotomy patients experience less pain than other surgical patients. ${ }^{1}$ However, more recent studies suggest that up to two-thirds of post-craniotomy patients experience moderate to severe pain, ${ }^{2}$ which is often poorly managed.

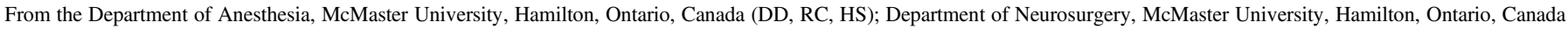

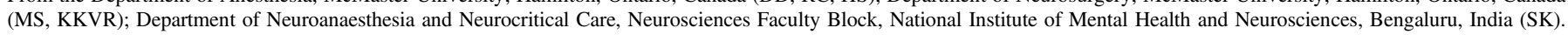
Received December 21, 2018. Final Revisions Submitted April 4, 2019. Date of Acceptance April 13, 2019.

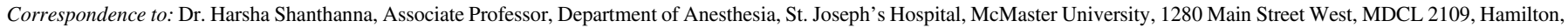
ON L8S 4K1, Canada. Fax: 905-523-1224. Email: shanthh@mcmaster.ca. 
Opioids are the most commonly used agents for treating moderate to severe post-surgical pain. In the neurosurgical population, opioids have the potential to interfere with neurological monitoring, can cause respiratory depression leading to hypercapnia, increased cerebral blood flow and ultimately increased intracranial pressure, and can mask early signs of intracranial complications. ${ }^{3}$ Furthermore, opioids are associated with several known adverse effects. Undertreatment of postcraniotomy pain can also lead to sympathetic stimulation leading to hypertension and intracranial hemorrhage. ${ }^{4}$ As a consequence of these conflicting scenarios and emerging interest in avoiding opioids, there is greater emphasis on non-opioid alternatives, as well as growing interest in the use of opioid-free anesthesia and perioperative analgesia. ${ }^{5,6}$ This concept has been applied to other surgical areas such as cholecystectomies, bariatric surgery, head and neck surgeries, and others. ${ }^{3,7-9}$ However, the available published studies surrounding the management of post-craniotomy pain have yielded inconsistent results. ${ }^{10}$ Hence, we decided to focus our review on opioid-free postoperative analgesia, which could include the use of regional blockade as well as other nonopioid analgesics. In our study we chose to focus on supratentorial craniotomies since these are a relatively homogenous patient population with perhaps the least severe post-operative pain. If we could eliminate the need for opiates for these patient it would help improve post-operative neurological examination significantly and hopefully decrease the number of investigations (e.g. computed tomography [CT] scans) due to more reliable clinical examination. ${ }^{1-14}$ Studies show that when looking at the different sites for craniotomies, the muscle dissection involved in posterior fossa craniotomies leads to a relatively higher postoperative pain experience. ${ }^{11-13}$ Similarly, patients with vascular malformations and/or cerebral aneurysms were excluded as they tend to require more postoperative analgesia to achieve pain control compared with their tumor counterparts. ${ }^{15}$ Associated cerebral vasospasm and hydrocephalus may also introduce considerable heterogeneity. ${ }^{16-19}$ Thus, the objectives of this systematic review were: (1) to compare the effectiveness of non-opioid and opioid analgesia in the treatment of post-craniotomy pain and (2) to identify available options for opioid-free analgesia postcraniotomy and consider clinical pathways for their effective use. Our secondary objective was to compare adverse effects between opioid and non-opioid analgesia groups.

\section{Methods}

\section{Design}

We undertook a systematic review of randomized controlled trials (RCTs) and constructed a narrative synthesis of results and available options.

\section{Search Strategy}

We conducted a comprehensive search of MEDLINE, Cochrane, and EMBASE databases from their inception to February 14, 2017. We used relevant keywords and medical subheadings to look for RCTs comparing opioid versus nonopioid post-operative analgesia for supratentorial craniotomies for elective tumor resections. We chose to focus on supratentorial craniotomies specifically as they result in relatively less pain compared to other craniotomy sites and therefore have the highest potential for completely opioid-free techniques. The full search terms and strategy are provided in the Supplementary Appendix. The search strategy was developed by input from physicians and further refined for each database in consultation with an experienced librarian. Using paired reviewers screening independently (DD and MS) and in duplicate, study selection was performed in two stages. Titles and abstracts were screened in the first stage, mainly looking for articles to exclude based on incorrect study design (i.e. non-RCT), language (i.e. non-English), and population. Any articles which were deemed to have incomplete information based on title and abstract or those that may fulfill at least the minimum criteria for inclusion were further screened in the second stage. The second stage involved full-text screening of potentially eligible citations, looking for articles that had comparators of interest (opioid vs non-opioid) and surgical site of interest. Disagreements were resolved by consensus between the two reviewers, and any unresolved decisions were decided by HS. A Cohen's kappa statistic on the full article final decision was estimated as a measure of interobserver agreement. A final search through the gray literature was performed by searching through Google Scholar, Web of Science, and manually screening referenced articles in each of the RCTs included in this review.

\section{Study Selection}

We searched for English-language RCTs comparing opioid to non-opioid post-operative analgesia for supratentorial craniotomies. For the non-opioid group, studies were included if they used only short-acting opioid agents for intraoperative analgesia and excluded if they used long-acting agents or administered any opioid after extubation. We also excluded observational studies, quasi-randomized studies, and studies in which the study population included infratentorial pathology, aneurysms or vascular malformations, or emergency surgeries. Whenever full reports were not available, authors were contacted.

\section{Data Collection}

The same pair of reviewers extracted the data independently and in duplicate, using data extraction forms created in Microsoft Excel (Ver 15.28) that were piloted between the reviewers for consistency and accuracy. Data items extracted from each study included study characteristics, risk of bias (RoB) items, demographic information, participant disposition through the study, and our review outcomes in continuous and binary measures.

\section{RoB in Individual Studies}

RoB was assessed using the Cochrane Collaboration's tool for assessing RoB in randomized trials ${ }^{20}$ to capture the components of random sequence generation; allocation concealment; blinding of participants; blinding of outcome assessment; and analysis of incomplete outcome data. No attempt was made to contact authors for clarification on the RoB items. Selective outcome reporting was judged based on the outcomes described in the Methods section but not reported in the Results section.

\section{Outcomes}

We were interested in studies that provided opioid-free analgesia post-operatively, with or without the use of regional 
blockade. The effectiveness of opioid-free analgesia was assessed by comparing either (1) use of rescue analgesia or (2) postoperative pain scores. In one study, pain scores were presented in a graphical format; therefore, we used online software (https: //apps.automeris.io/wpd/) to extract data points. We decided a priori that we would combine studies (meta-analysis) if there were two or more studies using similar modalities to avoid opioid use. Our secondary objective included comparison of adverse effects including post-operative nausea and vomiting (PONV), sedation, itching, respiratory depression, and hemodynamic parameters as well as potential irritation at the site of the scalp blocks.

\section{Data Analysis and Reporting}

Considering the limited number of studies and associated heterogeneity, we decided to not pool data; hence, the outcomes are reported as tables and relevant outcomes for each study are summarized. Comparative effectiveness is reported either as proportion of patients with successful outcomes or as mean or median scores. Precision was reported using 95\% confidence intervals (CI) around the effect estimate.

\section{Narrative Synthesis of Available Options}

Based on the existing literature, we give a brief description of individual options that could be used in various phases of surgery, as a multimodal concept, to allow for opioid-free anesthesia or analgesia. We summarize the individual agents and their possible considerations for clinical use.

\section{Results}

\section{Study Characteristics}

A total of 467 citations were identified through the literature search (Figure 1), of which 53 studies were selected for full-text review (kappa $=0.64 ; \mathrm{CI}=0.54,0.75$ ). Subsequently, four studies (Table 1) were ultimately selected for inclusion in the systematic review (kappa $=0.88 ; \mathrm{CI}=0.64,1.11$ ). Two studies compared opioid to non-opioid drugs ${ }^{21,22}$ and two studies compared opioids to regional scalp blocks (RSB) ${ }^{23,24}$ In three of the four studies, patients reported pain using a visual analog scale score, ${ }^{21,22,24}$ one study used the numerical rating score to quantify pain. ${ }^{1}$ Both scoring systems ranged from 0 to 10 .

\section{Methodological Quality}

The RoB assessment is presented in Table 2. Reporting of methodological details of the trials was generally incomplete. All included trials were randomized; however, for all but one study, ${ }^{24}$ it was unclear how randomization was achieved. Only two studies commented on how allocation concealment was achieved. ${ }^{22,24}$ In two studies, ${ }^{21,22}$ blinding of participants and personnel was unclear and in three studies, blinding of outcome assessment was unclear. ${ }^{21-23}$ Outcome data collection was generally complete and no loss to follow-up was observed in any of the studies.

\section{Pain Scores}

Table 3 shows outcomes of interest in all included studies. In one of the studies, ${ }^{22}$ pain scores were not reported at 1-h and 24-h post-operatively. Furthermore, Biswal et al. ${ }^{24}$ showed pain scores in the form of a graph only; thus, numbers were extrapolated for this study as the original authors no longer had access to their original data. For studies that reported pain scores (ranging from 0 to 10), none had a statistically significant difference between opioid and non-opioid analgesia for post-craniotomy pain when compared at 1-h and 24-h post-operatively (Table 3 and Figure 2).

\section{Analgesia Requirements}

Use of supplemental analgesia was reported for three of the four included trials ${ }^{22-24}$ (Table 3). In two of the three studies, no statistically significant difference in the time to rescue analgesia or the amount of rescue analgesia was noted between patients who were allocated to receive opioids and those who received non-opioid treatments. One study ${ }^{22}$ found a statistically significant delay in the time to rescue analgesia among patients who were given opioids.

\section{Adverse Events}

\section{Post-Operative Nausea and Vomiting}

The incidence of PONV was reported in all but one study. ${ }^{24}$ This is shown in Table 3. Two of the three studies that compared the incidence of PONV in opioid versus non-opioid groups did observe a trend toward a decrease in PONV among patients who did not receive opioids, although the differences were not statistically significant. ${ }^{21,22}$

\section{Adverse Events Related to Scalp Blocks}

Biswas et al. ${ }^{24}$ observed no incidence of hematoma formation due to unsatisfactory hemostasis. Ayoub et al. ${ }^{23}$ did not report any adverse events related to scalp blocks.

\section{Discussion}

In this systematic review, we compared the effect of opioid versus non-opioid analgesia in the treatment of post-craniotomy pain. We identified four RCTs, of which two compared opioids to RSB. The other two studies compared acetaminophen or dexmedetomidine as non-opioid analgesics and did not show any superiority over the opioid group. As opioids are known to be superior to other agents for pain control, we expected studies to be designed for testing equivalency or non-inferiority. However, we did not find any such studies.

\section{Pain Scores}

The findings of this systematic review indicate that pain scores did not significantly differ between patients who received opioid analgesia and those who received non-opioid agents. Similarly, there was no difference in the incidence of PONV between those who were administered opioids and those who were given nonopioid medications. However, it is worth noting that Turgut et al. ${ }^{22}$ observed a statistically significant delay in the need for rescue analgesia for patients who received opioids compared to those who did not.

To the best of our knowledge, this is the first systematic review to compare the use of opioid versus non-opioid analgesia for post-craniotomy pain. A meta-analysis on the use of RSB for 
Table 1: Characteristics of included trials

\begin{tabular}{|c|c|c|c|c|c|c|}
\hline Author/Year & Sample Size & No. of Study Arms & Opioid & Non-opioid & Regional Scalp Block & Timing \\
\hline Biswas et al., 2003 & 41 & 2 & Fentanyl & & $\begin{array}{r}25 \mathrm{~mL} 0.25 \% \\
\text { Bupivacaine }\end{array}$ & Pre-incision \\
\hline Ayoub et al., 2006 & 50 & 2 & Morphine & & $10 \mathrm{~mL} 2 \%$ Lidocaine & End of surgery \\
\hline Turgut et al., 2009 & 50 & 2 & Remifentanil & Dexmedetomidine & & \\
\hline \multirow[t]{2}{*}{ Hassani et al., 2015} & \multirow[t]{2}{*}{45} & \multirow[t]{2}{*}{3} & Sufentanil & \multirow[t]{2}{*}{ Acetaminophen } & & \\
\hline & & & Morphine & & & \\
\hline
\end{tabular}

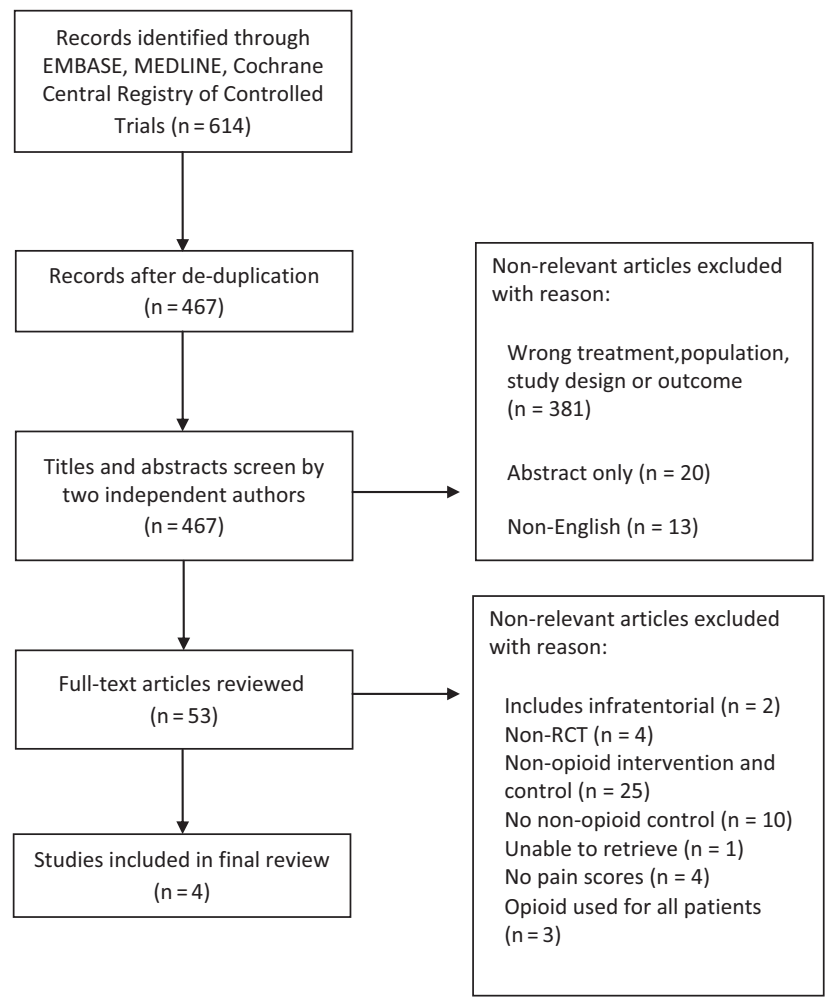

Figure 1: Study flow chart indicating study selection.

post-craniotomy analgesia demonstrated significant reductions in pain scores in patients who received RSB. ${ }^{25}$ Furthermore, RSB was not associated with adverse events. However, unlike our review, that review included any study that compared regional blockade with non-regional blockade. Similarly, dexmedetomidine has been investigated and found to reduce post-operative opioid consumption and the incidence of PONV when used as an anesthetic adjuvant in intracranial procedures. ${ }^{26,27}$

\section{Multimodal Analgesia}

It is widely known that multimodal analgesia improves pain while decreasing opioid requirements in a variety of postsurgical populations. ${ }^{28-30}$ Minimizing the use of opioids reduces their side effects, which can range from pruritus and gastrointestinal disturbances to significant respiratory depression. More importantly, in the setting of craniotomies, any reduction in the use of opioids can help to optimize postsurgical neurologic monitoring. Multimodal analgesia can comprise regional and neuraxial techniques, and non-opioid medications. In another center, a multimodal, interdepartmental, standardized analgesia protocol has been demonstrated to reduce post-operative pain among neurosurgical patients, improve documentation, and increase use of multimodal analgesia, including use of non-steroidal anti-inflammatory drugs and gabapentin. ${ }^{31}$ Furthermore, adherence to protocol was associated with a significant reduction in monthly use of naloxone, indicating a safety improvement. Other multimodal analgesia protocols have similarly been implemented in various surgical populations with good success. ${ }^{29,30,32}$ Table 4 summarizes the commonly used non-opioid analgesic agents that have been described in the literature as part of multimodal analgesia. 
Table 2: Risk of bias assessment

\begin{tabular}{l|l|l|l|l|l|l|l}
\hline Author/Year & $\begin{array}{c}\text { Random Sequence } \\
\text { Generation }\end{array}$ & $\begin{array}{c}\text { Allocation } \\
\text { Concealment }\end{array}$ & $\begin{array}{c}\text { Blinding of } \\
\text { Participants and } \\
\text { Personnel }\end{array}$ & $\begin{array}{c}\text { Blinding of } \\
\text { Outcome } \\
\text { Assessment }\end{array}$ & $\begin{array}{c}\text { Incomplete } \\
\text { Outcome Data }\end{array}$ & Selective Reporting & Other Bias \\
\hline Biswas et al., 2003 & & & & & & & \\
\hline Ayoub et al., 2006 & & & & & & & \\
\hline Turgut et al., 2009 & & & & & & & \\
\hline Hassani et al., 2015 & & & & & \\
\hline
\end{tabular}

Low Risk Unclear Risk

Table 3: Comparison of study outcomes

\begin{tabular}{|c|c|c|c|c|c|c|c|c|c|c|c|c|}
\hline \multirow[t]{3}{*}{ Study } & & \multicolumn{4}{|c|}{ Pain Score } & \multicolumn{2}{|c|}{ \% with PONV 24 h Post-op } & \multicolumn{5}{|c|}{ Rescue Analgesia Use } \\
\hline & & \multicolumn{2}{|c|}{ Opioid } & \multicolumn{2}{|c|}{ Non-opioid } & \multirow[t]{2}{*}{ Opioid } & \multirow[t]{2}{*}{ Non-opioid } & \multirow[t]{2}{*}{$\begin{array}{c}\text { Rescue } \\
\text { Analgesia }\end{array}$} & \multicolumn{2}{|c|}{$\begin{array}{l}\text { Delay Before 1st } \\
\text { Dose of Rescue } \\
\quad(\min )\end{array}$} & \multicolumn{2}{|c|}{$\begin{array}{l}\text { Cumulative Rescue } \\
\text { Dose at } 12 \mathrm{~h} \\
\text { Post-op (mg) }\end{array}$} \\
\hline & $\begin{array}{l}\text { Measure of } \\
\text { pain }\end{array}$ & $\begin{array}{c}1 \mathrm{~h} \\
\text { post-op }\end{array}$ & $\begin{array}{c}24 \mathrm{~h} \\
\text { post-op }\end{array}$ & $\begin{array}{c}1 \mathrm{~h} \\
\text { post-op }\end{array}$ & $\begin{array}{c}24 \mathrm{~h} \\
\text { post-op }\end{array}$ & & & & Opioid & $\begin{array}{l}\text { Non- } \\
\text { opioid }\end{array}$ & Opioid & $\begin{array}{l}\text { Non- } \\
\text { opioid }\end{array}$ \\
\hline $\begin{array}{l}\text { Biswas et al., } \\
2003\end{array}$ & $\begin{array}{c}\operatorname{VAS}(0-10 \mathrm{~cm} \text {, } \\
\text { mean })\end{array}$ & $3.2^{\mathrm{a}}$ & $3.11^{\mathrm{a}}$ & $3.45^{\mathrm{a}}$ & $2.9^{\mathrm{a}}$ & \multicolumn{2}{|c|}{ NA } & Diclofenac & 60 & 105 & $58 \pm 10.8$ & $59 \pm 11.1$ \\
\hline $\begin{array}{l}\text { Ayoub et al., } \\
2006\end{array}$ & $\begin{array}{l}\text { NRS }(0-10 ; \\
\text { median) }\end{array}$ & 5 & 3 & 6 & 2 & 52 & 72 & Codeine & 30 & 45 & $113.6 \pm 74.8$ & $\begin{array}{c}144.8 \pm \\
71.7\end{array}$ \\
\hline $\begin{array}{l}\text { Turgut et al., } \\
2009\end{array}$ & & \multicolumn{4}{|c|}{ NA } & 10 & 4 & $\begin{array}{c}\text { Tramadol } \\
\text { (PCA) }\end{array}$ & $38.04 *$ & $33.68^{*}$ & \multicolumn{2}{|l|}{ NA } \\
\hline \multirow{2}{*}{$\begin{array}{l}\text { Hassani et al., } \\
2015\end{array}$} & \multirow{2}{*}{$\begin{array}{l}\text { VAS }(0-10 \mathrm{~cm} \text {; } \\
\text { mean of } \\
\text { scores } \\
\text { collected at } \\
0,2,4,12, \\
24-\mathrm{h})\end{array}$} & \multicolumn{2}{|c|}{1.7 (sufentanil) } & \multirow{2}{*}{\multicolumn{2}{|c|}{3.2}} & 24 (sufentanil) & \multirow[t]{2}{*}{15.66} & \multirow{2}{*}{\multicolumn{5}{|c|}{ NA }} \\
\hline & & $2.3(\mathrm{~m}$ & orphine) & & & 97.6 (morphine) & & & & & & \\
\hline
\end{tabular}

NA = not applicable; NRS = Numerical Rating Score; VAS = Visual Analog Score; PCA = patient-controlled analgesia; PONV = post-operative nausea and vomiting

${ }^{a}$ numbers extrapolated from graph.

$* p<0.05$.

The use of multimodal analgesia has also become increasingly popular with the concurrent evolution of the opioid epidemic. ${ }^{33,34}$ It is well known that opioid prescription following surgery can potentially lead to long-term use and can be a significant source of misuse and abuse. This is especially true for a few subsets of the population, including acute post-surgical patients. ${ }^{35}$ Therefore, opioid-sparing techniques can have positive public health implications.

In an era when hospital length of stay continues to decrease despite an increasing number of more complex surgical procedures, self-administration of opioids at home is now a routine practice. The safety of such practice is questionable as opioids are associated with many adverse effects, including breathing impairment and constipation. These adverse events can lead to the need for admission to hospital and thereby augment the economic burden associated with their management. ${ }^{36,37}$ Further, surplus unconsumed opioids can become a source for misuse by patients or others, and problems with nonmedical use.

\section{Limitations}

Our review has several limitations. The scope of this review was restricted only to post-operative analgesia, yet the use of intraoperative opioids may have a bearing on the development of PONV and other perioperative complications. Additionally, our review was based on a limited number of studies, most of which had inherent biases.

\section{Conclusions}

In summary, our review suggests that both opioids and nonopioid options, such as dexmedetomidine and RSB, can provide at least comparative pain relief with similar side effect profiles. As opioids can profoundly interfere with neurologic monitoring 
Table 4: Non-opioid medications that can be considered for use in a multimodal analgesic pathway

\begin{tabular}{|c|c|c|c|c|c|}
\hline Medication & Operative Phase & Mechanism of Action & Dose & Method of Use & Safety Considerations \\
\hline $\begin{array}{r}\text { Acetaminophen } \\
\text { (Paracetamol) }\end{array}$ & Pre-op, post-op & $\begin{array}{c}\text { Inhibits central COX-3, } \\
\text { activates descending } \\
\text { serotonergic pathways }\end{array}$ & $0.5-2 \mathrm{~g}$ & $\mathrm{PO} / \mathrm{PR}$ & Hepatotoxicity \\
\hline NSAIDs & Pre-op, post-op & $\begin{array}{l}\text { Inhibit prostaglandin } \\
\text { production to decrease } \\
\text { inflammation }\end{array}$ & $\begin{array}{l}\text { Ketorolac } 15-30 \mathrm{mg} \\
\text { Diclofenac } 50-100 \mathrm{mg}\end{array}$ & $\mathrm{PO} / \mathrm{IV} / \mathrm{PR}$ & $\begin{array}{l}\text { GI disturbances, bleeding } \\
\text { risk, renal dysfunction }\end{array}$ \\
\hline Selective COX-2 inhibitors & Pre-op, post-op & $\begin{array}{l}\text { Inhibit prostaglandin } \\
\text { production; compared to } \\
\text { NSAIDs, selectivity for } \\
\text { COX-2 decreases risk of } \\
\text { peptic ulcers }\end{array}$ & Celecoxib 100-200 mg & $\mathrm{PO}$ & Thromboembolic risk \\
\hline Dexamethasone & Pre-op & Mineralo-glucocorticoid & $4-8 \mathrm{mg}$ & IV & $\begin{array}{l}\text { Immunosuppression, } \\
\text { hyperglycemia }\end{array}$ \\
\hline Gabapentinoid & Pre-op, post-op & $\begin{array}{l}\text { Binds to pre-synaptic } \\
\text { voltage-gated calcium } \\
\text { channels }\end{array}$ & $\begin{array}{l}150 \mathrm{mg} \text { Pregabalin } \\
300 \mathrm{mg} \text { Gabapentin }\end{array}$ & $\mathrm{PO}$ & Drowsiness, somnolence \\
\hline Ketamine & Intra-op, post-op & NMDA receptor antagonist & $10-20 \mathrm{mg}$ & PO/IV boluses/IV infusion & $\begin{array}{l}\text { Dysphoria, increase in } \\
\text { intracranial pressure }\end{array}$ \\
\hline Dexmedetomidine & Intra-op & Alpha-2 adrenergic agonist & $0.2-1 \mu \mathrm{g} / \mathrm{kg} / \mathrm{h}$ & IV infusion & Hypotension \\
\hline Lidocaine & $\begin{array}{l}\text { Pre-op scalp infiltration by } \\
\text { surgeon, intra-op, post-op }\end{array}$ & Sodium channel blocker & $0.5 \%-2 \%$ & $\begin{array}{l}\text { IV boluses/IV infusion/ } \\
\text { nerve block }\end{array}$ & $\begin{array}{l}\text { Local anesthetic systemic } \\
\text { toxicity }\end{array}$ \\
\hline
\end{tabular}

$\mathrm{COX}=$ cyclooxygenase; $\mathrm{GI}=$ gastrointestinal; Intra-op = intraoperatively; IV = intravenous; NMDA = N-methyl-D-aspartate; NSAIDs = non-steroidal anti-inflammatory drugs; Pre-op = pre-operative; PO = per os; Post-op = post-operative; PR = per rectum.

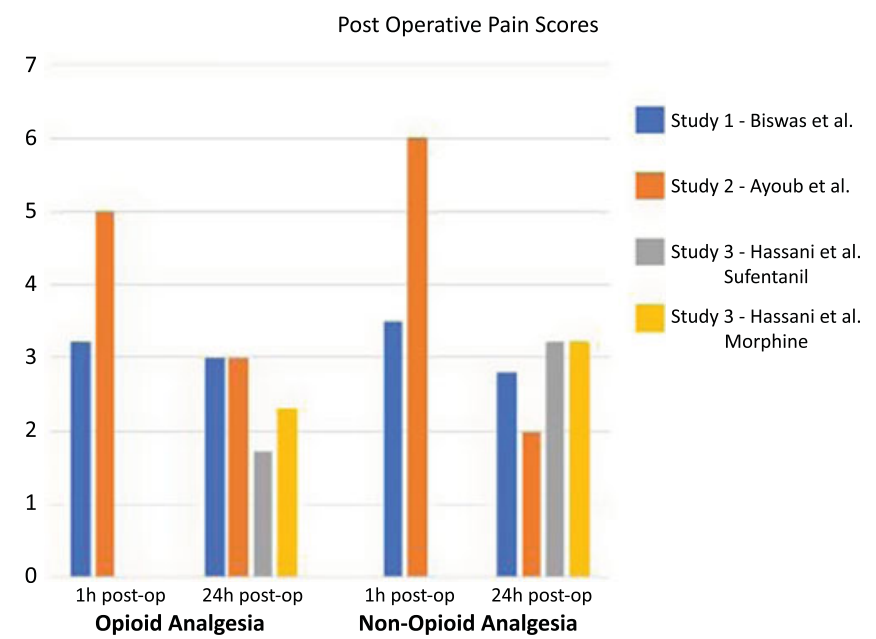

Figure 2: This figure illustrates a comparison between opioid and nonopioid analgesia used in three studies identified in this review. The studies by Biswas et al. and Ayoub et al. compared opioids versus nonopioids within 1 h from surgery and 24-h post-surgery. They found no significant difference in pain control between both studies. The study by Hassani et al. compared two different opioids (sufentanil and morphine) with non-opioid analgesia $24-h$ post-operatively and found no difference between opioids and non-opioids.

post-operatively, the use of multimodal analgesia is attractive in the neurosurgical patient. Nevertheless, given the small sample sizes of available RCTs, there is insufficient evidence to conclude that these opioid-sparing strategies are effective at this point in time. Further research with large sample sizes are required to determine the efficacy of these techniques. Future studies should also look to identify whether using alternate modalities of analgesia (non-opioid alternatives) would reduce hospital length of stay and the use of unnecessary CT scans.

\section{Supplementary Material}

To view supplementary material for this article, please visit https://doi.org/10.1017/cjn.2019.57 


\section{ACKNOWLEDGMents}

We thank Sara Miller M.Sc., Scientific Editor, Department of Anesthesia - Research Office, McMaster University for editing this manuscript.

\section{FUNDING}

HS is supported by the Canadian Anesthesia Research Foundation through the Career Scientist Award, 2018-2020.

\section{Disclosures}

The authors report no conflicts of interest.

\section{Statement of Authorship}

DD: Analysis and Interpretation of Data, Drafting the Article, Critically Revising the Article, Reviewed the submitted version of manuscript.

MS: Analysis and Interpretation of Data, Drafting the Article, Critically Revising the Article, Reviewed the submitted version of manuscript.

RC: Acquisition of Data, Review of the manuscript.

SK: Critically Revising the Article.

KKVR: Conception and Design, Critically Revising the Article, Reviewed the submitted version of manuscript, Study supervision.

HS: Conception and Design, Critically Revising the Article, Reviewed the submitted version of manuscript, Study supervision. and support including additional material or technical support.

All authors have read and approved the final version of the manuscript.

\section{REFERENCES}

1. Dunbar PJ, Visco E, Lam AM. Craniotomy procedures are associated with less analgesic requirements than other surgical procedures. Anesth Analg. 1999;88(2):335-40.

2. De Benedittis G, Lorenzetti A, Migliore M, Spagnoli D, Tiberio F, Villani RM. Postoperative pain in neurosurgery: a pilot study in brain surgery. Neurosurgery. 1996;38(3):469-70.

3. Gottschalk A, Yaster M. The perioperative management of pain from intracranial surgery. Neurocrit Care. 2009;10(3):387-402.

4. Basali A, Mascha EJ, Kalfas I, Schubert A. Relation between perioperative hypertension and intracranial hemorrhage after craniotomy. Anesthesiology. 2000;93(1):48-54.

5. Brandal D, Keller MS, Lee C, et al. Impact of enhanced recovery after surgery and opioid-free anesthesia on opioid prescriptions at discharge from the hospital: a historical-prospective study. Anesth Analg. 2017;125(5):1784-92.

6. White PF. The role of non-opioid analgesic techniques in the management of pain after ambulatory surgery. Anesth Analg. 2002;94(3):577-85.

7. Bakan M, Umutoglu T, Topuz U, et al. Opioid-free total intravenous anesthesia with propofol, dexmedetomidine and lidocaine infusions for laparoscopic cholecystectomy: a prospective, randomized, double-blinded study. Braz J Anesthesiol. 2015;65(3):191-9.

8. Tripathy S, Rath S, Agrawal S, et al. Opioid-free anesthesia for breast cancer surgery: an observational study. J Anaesthesiol Clin Pharmacol. 2018;34(1):35-40.

9. Ziemann-Gimmel P, Hensel P, Koppman J, Marema R. Multimodal analgesia reduces narcotic requirements and antiemetic rescue medication in laparoscopic Roux-en-Y gastric bypass surgery. Surg Obes Relat Dis. 2013;9(6):975-80.

10. Haldar R, Kaushal A, Gupta D, Srivastava S, Singh PK. Pain following craniotomy: reassessment of the available options. Biomed Res Int. 2015;2015:509164.

11. Flexman AM, Ng JL, Gelb AW. Acute and chronic pain following craniotomy. Curr Opin Anaesthesiol. 2010;23(5):551-7.

12. Gottschalk A, Berkow LC, Stevens RD, et al. Prospective evaluation of pain and analgesic use following major elective intracranial surgery. J Neurosurg. 2007;106(2):210-6.

13. Thibault M, Girard F, Moumdjian R, Chouinard P, Boudreault D, Ruel M. Craniotomy site influences postoperative pain following neurosurgical procedures: a retrospective study. Can J Anaesth. 2007;54(7):544-8.

14. Dolmatova EV, Imaev AA, Lubnin AY. 'Scheduled' dosing of lornoxicam provides analgesia superior to that provided by 'on request' dosing following craniotomy. Eur J Anaesthesiol. 2009;26(8):633-7.

15. Glisic EK, Gardiner L, Josti L, et al. Inadequacy of headache management after subarachnoid hemorrhage. Am J Crit Care. 2016;25(2):136-43.

16. Chen S, Luo J, Reis C, Manaenko A, Zhang J. Hydrocephalus after subarachnoid hemorrhage: pathophysiology, diagnosis, and treatment. Biomed Res Int. 2017;2017:8584753.

17. Dash H. Recent advances in the management of post-operative intracerebral vasospasm. J Neuroanaesthesiol Crit Care. 2017;4(4):56-9.

18. Garg R, Bar B. Systemic complications following aneurysmal subarachnoid hemorrhage. Curr Neurol Neurosci Rep. 2017;17(1):7.

19. Roos YB, de Haan RJ, Beenen LF, Groen RJ, Albrecht KW, Vermeulen M. Complications and outcome in patients with aneurysmal subarachnoid haemorrhage: a prospective hospital based cohort study in the Netherlands. J Neurol Neurosurg Psychiatry. 2000;68(3):337-41.

20. Higgins JP, Altman DG, Gotzsche PC, et al. The Cochrane Collaboration's tool for assessing risk of bias in randomised trials. BMJ. 2011;343:d5928.

21. Hassani E, Mahoori A, Sane S, Tolumehr A. Comparison the effects of paracetamol with sufentanil infusion on postoperative pain control after craniotomy in patients with brain tumor. Adv Biomed Res. 2015;4:64

22. Turgut N, Turkmen A, Ali A, Altan A. Remifentanil-propofol vs dexmedetomidine-propofol-anesthesia for supratentorial craniotomy. Middle East J Anaesthesiol. 2009;20(1):63-70.

23. Ayoub C, Girard F, Boudreault D, Chouinard P, Ruel M, Moumdjian R. A comparison between scalp nerve block and morphine for transitional analgesia after remifentanil-based anesthesia in neurosurgery. Anesth Analg. 2006;103(5): 1237-40.

24. Biswas BK, Bithal PK. Preincision $0.25 \%$ bupivacaine scalp infiltration and postcraniotomy pain: a randomized double-blind, placebo-controlled study. J Neurosurg Anesthesiol. 2003; 15(3):234-9.

25. Guilfoyle MR, Helmy A, Duane, D, Hutchinson PJ. Regional scalp block for postcraniotomy analgesia: a systematic review and meta-analysis. Anesth Analg. 2013;116(5):1093-102.

26. Peng K, Jin XH, Liu SL, Ji FH. Effect of intraoperative dexmedetomidine on post-craniotomy pain. Clin Ther. 2015;37(5): 1114-1121.e1.

27. Song J, Ji Q, Sun Q, Gao T, Liu K, Li L. The opioid-sparing effect of intraoperative dexmedetomidine infusion after craniotomy. J Neurosurg Anesthesiol. 2016;28(1):14-20.

28. Horlocker TT, Hebl JR, Kinney MA, Cabanela ME. Opioid-free analgesia following total knee arthroplasty - a multimodal approach using continuous lumbar plexus (psoas compartment) block, acetaminophen, and ketorolac. Reg Anesth Pain Med. 2002;27(1):105-8.

29. Lee KJ, Min BW, Bae KC, Cho CH, Kwon DH. Efficacy of multimodal pain control protocol in the setting of total hip arthroplasty. Clin Orthop Surg. 2009;1(3):155-60. 
30. Ng JJ, Leong WQ, Tan CS, et al. A multimodal analgesic protocol reduces opioid-related adverse events and improves patient outcomes in laparoscopic sleeve gastrectomy. Obes Surg. 2017;27(12):3075-81.

31. Titsworth WL, Abram J, Guin P, et al. A prospective time-series quality improvement trial of a standardized analgesia protocol to reduce postoperative pain among neurosurgery patients. J Neurosurg. 2016;125(6):1523-32.

32. Shi ZB, Dang XQ. Efficacy of multimodal perioperative analgesia protocol with periarticular medication injection and nonsteroidal anti-inflammatory drug use in total knee arthroplasty. Niger J Clin Pract. 2018;21(9):1221-7.

33. Kelly MA. Addressing the opioid epidemic with multimodal pain management. Am J Orthop (Belle Mead NJ). 2016;45(7):S6-S8.
34. Koepke EJ, Manning EL, Miller TE, Ganesh A, Williams DGA, Manning MW. The rising tide of opioid use and abuse: the role of the anesthesiologist. Perioper Med (Lond). 2018;7:16.

35. Noble M, Treadwell JR, Tregear SJ, et al. Long-term opioid management for chronic noncancer pain. Cochrane Database Syst Rev. 2010;(1):CD006605.

36. Kane-Gill SL, Rubin EC, Smithburger PL, Buckley MS, Dasta JF. The cost of opioid-related adverse drug events. J Pain Palliat Care Pharmacother. 2014;28(3):282-93.

37. Wan Y, Corman S, Gao X, Liu S, Patel H, Mody R. Economic burden of opioid-induced constipation among long-term opioid users with noncancer pain. Am Health Drug Benefits. 2015;8(2):93-102. 